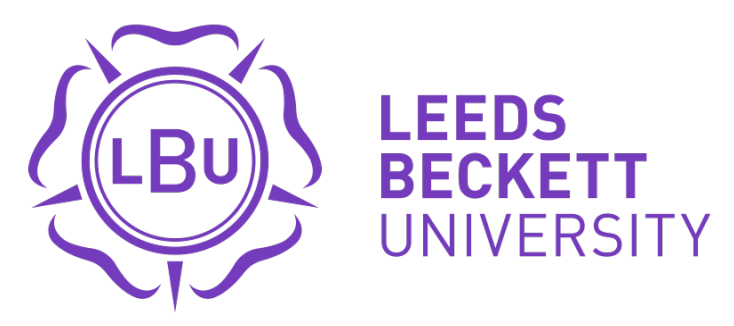

Citation:

Abram, S (2014) The time it takes: Temporalities of planning. Journal of the Royal Anthropological Institute, 20 (S1). 129 - 147. ISSN 1359-0987 DOI: https://doi.org/10.1111/1467-9655.12097

Link to Leeds Beckett Repository record:

https://eprints.leedsbeckett.ac.uk/id/eprint/1367/

Document Version:

Article (Accepted Version)

The aim of the Leeds Beckett Repository is to provide open access to our research, as required by funder policies and permitted by publishers and copyright law.

The Leeds Beckett repository holds a wide range of publications, each of which has been checked for copyright and the relevant embargo period has been applied by the Research Services team.

We operate on a standard take-down policy. If you are the author or publisher of an output and you would like it removed from the repository, please contact us and we will investigate on a case-by-case basis.

Each thesis in the repository has been cleared where necessary by the author for third party copyright. If you would like a thesis to be removed from the repository or believe there is an issue with copyright, please contact us on openaccess@leedsbeckett.ac.uk and we will investigate on a case-by-case basis. 
Paper for 'Doubt, Conflict and Mediation: the anthropology of modern time' ESRC Seminar series. Published as: Abram, S. (2014) The time it takes: temporalities of planning. Journal Of The Royal Anthropological Institute, 20 April, pp. 129-147.

\section{The time it takes: temporalities of planning}

\section{Simone Abram}

In defining the modern, it would be uncontroversial to suggest that state planning is an archetypally modern expression of both time and space. The idea of improved futures to be achieved by the rational application of policy and the hygienic distribution of development is emblematic of a modern world view (see Rabinow 1989), even if practice may fall short of the high ideals that rational planning promises. Wittrock (2000) even locates the key identifier of modernity in the rise of promissory notes, of which governmental plans could be considered an example (see Abram and Weszkalnys in press). With its concern for improvements and with the future as its object, planning is, by definition, a temporal field, one that is concerned with transformation through time, or what Gisa Weszkalnys and I have described as 'the possibilities that time offers space' (Abram and Weszkalnys 2011:3). Notions of progress that are implicit to plans suggest that planning time is inherently modern, yet close attention to planning practices indicates that such temporalities are doubted, contested and mediated. Planning is in fact a particular form of governmental technology through which social discipline, ritual and rhythm are made present in social life, and in which time is materialized, mediated or brought into conflict. Planning technologies continue to colonize state practice, despite neo-liberal principles of minimizing the role of the state; indeed it appears that as the management of actual services is put out to contract, the role of the state is increasingly bound up in proliferating forms and domains of planning. Concrete modernist architectural city plans of the post-war era have given way to 'aspirational' regional socio-economic future-visions of the $21^{\text {st }}$ century. Planning is not going away.

Anthropological approaches to neoliberalized time suggest a break with modernity's temporalities, yet as land-use and development planning move into neo-liberalized forms, their temporal frames appear to become more abundant rather than being denuded. Movement into the future changes direction, with forecasting challenged by 'backcasting', and planning regulations being implemented retrospectively as well as through ordered progression in linear time. Planning for the future contains more forms of temporality than merely anticipation (c.f. Adams et al 2009). In contrast to the focus on predicting the future (e.g. Zaloom 2009) or anticipating potential events (Lakoff 2008), a closer look at both ordinary and particular planning practices demonstrates the variation and fecundity of temporal imagination and management that are found in both modern and neoliberal regimes. These have much more to tell us than of the relationship between technology and affect (c.f. Zaloom, op.cit.). Contemporary forms of planning continue to envisage long-term futures, and deal with immediate issues, but I argue that they do not evacuate the near-future of intention or activity, or of potential (c.f. Guyer 2007a). Instead, that near-future is becoming a different domain, whose authority is more dependent on appeals to the demonstrable participation of a putative public, while games of control and expertise continue to be played. If anything, it is the near and medium past that are evacuated from the practice of planning professionals and bureaucrats, their relentless focus on worlds yet to be and work yet to be done quickly leaving behind the meaningful past. It is in the encounter with 'ordinary people' - residents, protesters, 
participants - who bring an unruly past back into the planning process, that planning's selective technologies of moving through time are unsettled.

In this article, I consider the temporalities of democratic spatial planning, including holistic community planning and land-use planning in Norway and Sweden. While the term 'spatial' indicates a concern with land-use, urban design, spatial distribution of facilities and services, and concrete development, planning practice is full of temporal conundrums. Referring to various instances of planning practice, I will argue that conflicting temporal frames characterize contemporary urban and infrastructural planning, and that widespread forms and norms of social mediation adopted by planners falter through a lack of theoretical and practical attention to temporal contradictions. But first, I will briefly address some of the recent discussions of temporality that help to bring fresh insights into an analysis of planning, which in turn is a site of analysis that offers new dimensions to the understanding of time in anthropology.

\section{Near, present, future and horizons of time.}

Current discussions of time in contemporary anthropology have been spurred on by Jane Guyer's thoughts on changing regimes of time in relation to economics and evangelism (2007a). Guyer argues that economic theories and practices have shifted towards a monetarism that implements immediate controls over money supply with the aim of achieving stability over the very long term, thus evacuating the medium-term or the near-future of significance or potential for action. This shift away from medium-term regulation (the five-year plan, episodic looking forward and backward, the rational welfare state) is mirrored, in Guyer's analysis, by an evangelical Christian prophetic temporality, in which the lived present is an indeterminate time between the first and second comings, or between a historical past and a timeless future horizon. In this, too, the near future of the human lifetime is postponed in favour of the distant rapture, leaving a focus only on the imminent and stripping it of causalities.

Guyer is hardly alone in her concern for the changing political potential for the future. Pusey, for example, argued much earlier that a shift from public time towards market time is experienced as a shrinking horizon of meaningfully anticipated futures (1998). This temporal perspective is increasingly shared by other anthropologists. Baxstrom, for example, has argued that urban development plans in Kuala Lumpur operate in an everlasting present rather than 'towards an authoritarian, teleological sense of "the future"" (2012:135). Referring to this as a "baroque disposition' (Ibid.: 137), Baxstrom suggests that the primary role of these plans is to demonstrate mastery over a present that is enfolded and multiple, where buildings seem to be demolished and rebuilt at whim in what he calls the 'dizzying eventedness of the present' (Ibid.: 143). This eventedness does not quite correspond to Guyer's notion of punctuated calendar time, but the emphasis on events disconnected in time is shared. Stuff happens, they seem to say, even if we cannot make sense of their sequence.

Guyer's article also intimates a sense of loss in referring to the decline of the near future, of her sense of foreignness in the current present, and the evacuation of a temporal frame that allowed for 'planning and hoping, of tracing out mutual influences, of engaging in struggles for specific goals' (Guyer 2007a: 409). The mention of planning is instructive, since it is precisely in this middledistance future that one would expect the ambitions and hopes of spatial planning to be found. Yet even in Baxstrom's instrumental plans, the spectre of the future does not disappear from plans 
themselves. Plans always gesture towards some version or 'vision' of a future, even if this acts only as a vehicle for present action. It could be argued that the kind of future thus depicted might be changing, however. Halvard Vike notes a shifting of temporal horizons, in relation to Norwegian plans (in press). Inspired by Pusey's observations, Vike has suggested that the future experienced in the Norwegian welfare state is being redefined from an Enlightenment ideal of participatory planning as a means to achieve political mobilization and democratization towards a noeliberalization of planning as a managerial strategy. In Vike's analysis, the conceptualization of politics has been transformed from Utopian Time to Contemporary Time. Utopian Time, as the horizon of the possible, suggests collective movement along a path towards goals which motivate, offer hope, and may instill a degree of patience, even a willingness to make sacrifices towards the greater goal. Contemporary Time, on the other hand, as the temporal mode of market transactions implies a logic of immediate return, equivalent to Utopia Now, or in Norwegian terms, the immediate delivery of universal welfare as an individual right guaranteed by the state. As Vike notes, it becomes increasingly difficult to satisfy demands for utopia now with plans that propose an orderly transition towards better services in the future. These gaps between ideology and practice lead inexorably towards pragmatic attempts to tackle overloads in demand, and a corresponding disillusion with the making of visionary plans. If we can have utopia now, why wait? Without the rational link between future vision and action, long-term planning is easily seen as 'just words' (Ibid.).

And yet observing the world of European state planners today, there is little evidence of any decline in planning activity. On the contrary, over nearly two decades in which I have been observing planning, the numbers and kinds of plans demanded by the state have flourished. For instance, a recent law on planning in Norway proposes that each municipality should adopt a planning-strategy within a year of local elections, identifying strategic choices over social development (including long-term land-use, environmental challenges, and the need for further plans, see Miljøverndepartementet 2011). This meta-plan appears to be a tool to promote coordination between neighbouring districts and between the layers of governmental hierarchy, and as an immediate political evaluation scale - progress towards strategic aims identified at the start of one electoral period will provide benchmarks for the following election (see KS, undated). It does not replace the ambitious requirement for all Norwegian municipalities to produce comprehensive medium and long-term development plans, however. On the contrary, the new planning-strategy must take account of existing municipal plans, but while planning-strategies require broad public debate, they do not entail the same strict procedural inclusion, information and consultation procedures as municipal plans. How the four-year term of the planning strategy affects the twentyyear horizon of municipal planning remains to be seen, but it would appear that the planningstrategy is a means to fill the near-future with ever more alternative forms of organization rather than to empty it out (see Wilk 2007, Zaloom 2007).

Similarly, even though a new national planning framework for England proposes a blanket approval for 'sustainable development', potentially weakening planning control to the point of inutility, it still insists on a plan-led approach (DCLG 2012). Given the potentially radical changes currently proposed for planning in England (where the end of planning has been mooted among planning practitioners, pers.comm.), my intention is not to try to prophecy how these changes might emerge, but instead to consider some of the temporal schemes adopted in plan-led systems in the decades before and after the turn of the $21^{\text {st }}$ century, many of which remain in place at the time of writing. 
Plan-led systems, common at least to Northern European countries, presume a set of planning tools and practices revolving around visions of variably-distant futures. In both the UK and Scandinavia, for example, governmental planning systems have been seen by the centre-left political parties as a key route to securing a more participatory democracy, enthusiastically supported by planning theorists inspired by the participatory planning movements of the 1960s (see Damer and Hague 1971) and by the New Labour Government's 'modernising agenda', in which inclusive planning would contribute to democratic renewal (RTPI 2007).

The question that arises in for this article is whether the temporalities of planning have been evacuated from local government action in the way that Guyer argues that they have from state economics. While the normative academic literature of planning theory acknowledges that planning is a process that implies progress through time, the concept of conflicting temporalities is generally underemphasized in favour of questions of spatial justice. Yet games of temporality are constantly being played. New varieties of future horizon have emerged as well as disappeared, and models of the progression from one to another have been postulated, discarded and adopted. Political beliefs in participative planning have survived various attempts to create discursive forums, and futurevisioning and scenario techniques have come and gone. A brief survey of planning horizons also suggests a range of temporalities in play, that are fleetingly concretised into planning documents, documents which give the appearance of solidity and endurance, yet are constantly in the process of revision and reinvention.

There are, despite Guyer's concerns, near and medium term plans. Norwegian Municipal Plans, with their horizon of 15-20 years, or the English Local Development Frameworks with their 20-25 year Core Strategies are both revised more frequently, suggesting that the near future is still at least rhetorically present in local state planning in neoliberalizing (or, following Guyer, monetarized ${ }^{\mathrm{i}}$ ) economies. Norwegian local planning is marked by the 4-year electoral cycle and the annual financial plan. Annual planning takes the form of reporting of service-levels, revision of spending plans, and adjusting of service criteria. In other words, the long-term plan is implemented through shorter-term plans. Until the new planning-strategy comes into force (see above), planning beyond annual plans has been considered 'strategic'. Municipal plans, for example, are usually considered strategic, and take a standard (or one might argue hegemonic) form. An example from a wealthy district near Oslo begins with an outline of the municipality's vision of the future, clothed in the moralized rhetorics of well-being: 'everyone will have the opportunity for success in their own ambitions, wishes and desires ${ }^{\text {ii }}$. At the same time, challenges for the future are outlined, and some acknowledgement may be offered that the future may not always live up to the vision: 'Visions can never be realized, but serve as a guiding star and articulate an ambition'. After a general exposition of this strategic ambition, the plan lays out a series of policies with different temporal horizons. A general development plan includes broad development areas identified in maps covering a 30 year horizon, while more concrete policies propose to concentrate development in particular areas over the next 10 years. Specific developments are sometimes identified, but detailed architectural plans are not considered in the strategic plan. The plan projects forward up to 20 to 30 years, but is revised or rewritten over one or two electoral cycles, so a strategic plan never holds over the whole period of its strategy. While some policies might roll forward into a new plan, others may not, suggesting that there are parallel temporal flows. On the one hand, an imaginative future vision in the long term, which itself is revised on a shorter cycle. In the shorter term still, concrete projects are dealt with under a different temporal and spatial framework which is more immediate. And, in 
practice, imminent political decisions are taken that do not align with the ambitions outlined in the plans. Despite their sometimes grandiose pretentions, plans are not always sovereign.

It is worth noting an issue that we generally take for granted, that spatial and temporal plans are often scaled in proportion. Strategic planning should be large in both scales - a district-wide plan for a 20 year period might include a note on the development of a plot, but a detailed plan (blueprint) or architectural design for a specific plot to be built in the next year or two would rarely be considered strategic in its own right. The Norwegian plan mentioned above is explicit: the plan's society-section translates and concretises the vision, and the strategic direction and vision are operationalized through the implementation plan and annual reviews. Spatial and temporal scales thus shrink from the abstract vision to the concrete development. Another way to frame this would be to suggest that something one expects to happen in the foreseeable future cannot be seen as visionary. Setting out a plan to build a new office block in a town centre is unlikely to be seen to fulfill a vision of enabling people to achieve their ambitions and desires, or even to make the town the best in the country (another typical strategic planning goal), even if providing more office space for entrepreneurs is a medium-term aim.

These scaling effects were apparent in the preparation of a municipal plan that I followed in 2000 in the same Norwegian municipality ${ }^{\mathrm{iii}}$. A rural but urbanizing district with approximately 50,000 inhabitants that had expanded rapidly in the preceding decades from a comfortable agricultural district to a well connected set of commuter settlements, where average incomes were above the national mean and an increasing proportion of the population was over the age of 70 . The municipality was politically conservative, and in the period I was there was governed by a coalition of Conservative and populist Future parties. From the late 1990s, the chief-executive, supported by the mayor, introduced new organizational forms and policies that correspond to the New Public Management, a process that could be understood as a form of neoliberalization (see Abram 2002). In 2000, the process of preparing a new municipal plan had changed. Until then, municipal plans had generally been prepared by the Chief Planner, circulated for comments among directors of municipal departments (senior administrators) and presented to politicians for discussion and approval. 'Ours is a very written culture', the Chief Planner explained. Inspired by professional debates about inclusive planning, the Chief Planner had proposed a more comprehensive process, where participants would contribute to a more integrated vision of the municipality's future. At the same time, the Chief Executive, a great enthusiast for neoliberal public management, had been approached by a private consultant who argued that municipal planning would benefit from professional management. The consultant was contracted to deliver a new participative plan. His process demanded that a mixed group including both politicians and senior advisers should agree long-term goals, strategic objectives, and concrete policies to achieve them. The consultant was an experienced businessman nearing retirement age, who dressed in suit and tie, and made extensive use of detailed diagrams on powerpoint slides to demonstrate his ideas. Key words framed in differently coloured circles, with arrows from one to another popped up on the screen in front of a ambivalent group of local politicians and administrator in rather more relaxed attire. My observations of these meetings recall a sense of circularity and frustration, of people extremely politely resisting the pressure to conform to the consultant's desires, diverting the meetings through detailed discussion of particular municipal issues, and raising queries about the process wherever possible. 
The consultant constantly pushed to achieve a set of hierarchical aims, with an overall image of how the municipality should be in the future - 'a good municipality to live in', followed by closer definition of aspects of this future vision with the various municipal activities indicated in a new set of circles. Each activity was to have its own vision, and each should be identified by a series of elements that could be measured, such as the number of people qualified to do a particular job. And with this mapped out, a series of strategic challenges would emerge that were of more permanent concern in the municipality, each of which could have development goals, sub-goals and policies. Within this model, the overall aim was to organize all municipal activities into long-term general aims, and specific objectives. The consultant seemed to believe that the politicians could identify future visions, goals and objectives as 'resource persons' independent of their political views. One of the politicians from a small party (the Socialist Left) was concerned that issues under discussion should be shared with her party, and was afraid that when the plan came up for debate later, she would be told 'but you went along with the process Bente Skog iv, . Another minority party (Labour) politician agreed that if the small parties' views were ignored, they would relinquish any responsibility for the resulting documents. After a fairly lengthy discussion of roles, the consultant broke in to suggest that 'we have to move on, we need to run this process at a certain tempo'. Politicians who felt that their concerns were not represented in the aims identified need not worry, he suggested, since all their proposals had been noted and would be considered when the Chief Executive's team continued the planning work later. In addition, he remarked that these were issues that had been discussed several meetings earlier

Even in this short exchange, we can see time and process being folded and layered, and the near future being filled with concern and action. Municipal time is first layered and hierarchized, with near, middle and distant future scaled from concrete to abstract concerns. The practitioners attempt to draw routes through the hierarchy to join each concern in order of scale. But the neatness that the consultant sought was constantly challenged as politicians raised problems of integration between channels, seeking to reintroduce conflicting political positions, to cast doubt on decisions made, and remind the consultant of the requirements of democratic process. At the same time, the whole process was about time itself. What kind of future should they want for the municipality? How should that be prioritized and articulated? How much time should they give to the process of finding out? When should others have a chance to influence the process? How should time be managed?

One could interpret the situation as left-wing politicians attempting to recapture the near future as political control begins to disappear into contracts and competition. Locally, though, the concerns of those involved in the municipal planning process were not articulated in those terms. Bente expressed her concerns in a didactic way to the consultant, trying to be positive while explaining her reservations: 'I'm not really sure what I'm doing here, apart from that I think it's really interesting to be part of a discussion about the municipality's future, and I think it's great to look forward more than four years at a time, that's very valuable for me. But the political aspects - I have a party and a group who elected me, and who I represent, so it's a bit difficult to carry on.' Such a process should include time for her to consult her party colleagues and prepare a position. A correct schedule of action supports the democratic process, and most of those present had reservations about taking short-cuts. The mayor, himself, outlined the problem clearly enough: 'It's the overall aim that we politicians signal to the administration that we want, and the administration comes back with the policies that they think are right. They are best qualified to know which 
policies work best to reach our goals. So we can have a political discussion about what we think, and we have something to hang our debates on, but if we politicians should try to identify the right policies, I have a problem with that.' Not only should there be a correct division of labour, but also a correct order of events. Working towards a joint visionary plan that bypassed other systems would be a temporal problem, one would end up with a set of policies that did not coordinate with those coming from the administration, creating disruption and conflict. The political debating chamber was the arena designed to enable conflicts to be aired and resolved, and the political debate was the correct time to air such conflicts and disagreements. This alternative process appeared to be a kind of semi-private arena where the politicians were not present as elected representatives but as 'resource people', whose different concerns were reflected in the choice of majority-views as agreed aims, and their differences were hidden under broad thematic phrases. In effect, it cast doubt on their role, the legitimacy of the process, the meaning of the plan, what a private business consultant was doing steering the planning process, and how it would integrate with other formal democratic processes.

Parallel processes that failed to coordinate threaten the temporal coherence of bureaucratic life. Municipal organization is a constant balancing of temporal cycles and of managing the progression through interlocking activities, and of meeting successive deadlines. Deciding the annual budget unlocks the financing for services to be offered, and for the budget to be approved, detailed reports and policies must be prepared by different departments, each feeding in to the budget proposal. Each service also works to a committee cycle, through which any new proposal must pass, and at which each report must be approved. Progression through time is thus ordered into cyclical calendars, each of which must feed into the cyclic calendar of the primary committee, the general municipal council. Municipal council meetings are often seen as ritual formal events where prior work is passed through, but they are not necessarily empty rituals.

The Director of Technical Services explained this one evening during a council meeting. Taking a break from the slightly intense discipline of the council chamber, I slipped out into the town hall atrium, where coffee and pastries were laid out, as always, ready for the break. Council meetings were always open to the public who sat towards the back of the modernist, elegant concrete hall, austerely decorated with framed oil-portraits of former mayors. In the atrium, I found the Technical Director sitting back on one of the leather easy chairs listening to a discussion on the annual budget relayed from the chamber over loudspeakers. Asking him what he thought about the evening's meeting, he told me that you cannot understand his meeting in isolation, only as part of a broader series, both a series in time as a case passes from committee to committee and changes a little each time it is debated. But he also pointed to another temporal dimension, of experiential learning time, a time of cumulative knowledge gained through presence. Having sat through four yearly cycles of meetings, one learns to interpret the significance of what is being said, he explained. In that evening's meeting, for example, politicians who normally never talk about shifting significant sums of money between sectors were talking about moving millions of kroner. They were discussing taking money from reserves that the Chief Executive did not want them to use, and the Director interpreted it as a sign of their irritation that the Chief Executive had not offered them alternative budgets, as they would expect. Interpreting the Chief Executive's action as an attempt to hide money from them, they were discussing using large quantities of the very reserves he wanted them to save, to do what they wanted to do despite his obfuscation. The interpretation of this meeting as 
extraordinary was available only to someone with the knowledge of routine practice, and a deep understanding of routine was only available through experience of repetition.

Municipal time and planning time in this Norwegian local authority are both cyclical and hierarchical. Each consists of nested cyclical processes, both in the present and into the future, and each contributes to the creation of moral frames that are also nested and scaled. The aim of strategic planning is to try to maintain the hierarchy between immediate decisions and longer-term goals, to furnish immediate decisions and the near future with coherence by linking them with broader temporal horizons. Each step must be held within the reigns of democratic accountability, and each actor understands that they play a role as a representative of others. Politicians must refer to their parties, directors must seek professional advice from their staff. Requiring each detailed policy to acknowledge the abstract plan can be an effective governmental technology for keeping order in the diverse activities that fall within the remit of the municipality. But the form and content of strategic plans are constantly changing, under revised guidance from governmental agencies, or through the constant reinvention of local government management. The interlocking cogs of the municipal cycle are not static, like the cogs of a clock, but progressive, like the drive-wheels of a ship that propel it through the unpredictable waters of time, constantly under maintenance and upgrading of the engine. It is no coincidence that changing the strategic direction of a municipality is likened to turning a tanker - a process that takes some time, and requires many small adjustments of contributory motors if the turn is to be held in control. This is how it is broadly understood by municipal actors, and why it is misunderstood by the business consultant who tried to short-cut municipal planning process as though it were a free-standing business 'vision'. As one of the participants noted, democracy takes time; each participant has a hinterland of constituents to consult and confer with.

\section{Time as process, time as learning}

One of the great challenges for municipal planning time is to relate different temporal scales of procedural and lived time: how does one relate the horizon of a plan with the lived horizon of a citizen? One planner related his experience of consulting different local groups on the strategic plan of his small rural municipality. He was amused that the residents of the municipal elderly-care home agreed that the plan's aims were laudable, but found the twelve year horizon rather too long. The primary school children, on the other hand, found it barely imaginable, and produced drawings of steel and glass skyscrapers in the village as their imagined future. Planning trends favouring increased public participation in the production of strategic plans have only highlighted the difficulties of reconciling different temporal horizons, although the difficulties of participative planning are usually framed in terms of competing interests, or the need that planners feel to educate the public into planning practice ${ }^{\mathrm{v}}$.

The anthropological ideal that people should have some kind of sovereignty over their own development does not stand alone; calls for wider public participation in development and its planning were particularly vociferous in the 1960s (Skeffington 1969, Mogulof 1969, Arnstein 1969, Anton 1969). They found a new lease of life in the centre-left European governments from the mid-1990s and have since become a truism in planning studies. Participative planning is not one set of practices, but an umbrella term for the many forms of concern about how the 'public good' is explored, determined and negotiated in both general and specific terms. Whereas in development contexts, it has often been assumed that the community affected by development is self-evidently 
the local residents in the development site, in the Western planning context it is impossible to ignore the challenges that public participation poses for the very definition or model of democracy. While the discourse of participative planning conjectures an impersonal, disembodied public as the audience for planning processes, in practice, of course, this public is difficult to recognize in the face of the actual, embodied and particular persons who turn up to consultation events, for example, or who form campaign groups to challenge policies or decisions. A municipality may struggle to produce a suitable taxonomy through which to understand its public, leaving it struggling to produce the legitimacy it seeks for its actions (see Abram 2002). In the case of overarching infrastructure development, however, identifying a public and finding a way of building actual social relations with it presupposes a learning relationship on both sides. Theories and guides on public planning strongly advocate early and consistent participative practices, such that public concerns can be considered before the key early decisions are made, and public interest can be drawn into the planning, ensure that early objections can be co-opted and transformed into supportive criticism.

The kind of strategic plans being discussed in the municipality described above tend to be seen as controlling progression into a slowly emerging future, during which ordered communication between politicians, parties and constituents can be supplemented by direct surveys of 'user groups' for particular services, for example.

In the case of infrastructure plans, however, the future can appear to offer radical change, and the temporal horizon suddenly seems to expand. Rather than projecting forward over the years for a decade or two, the construction of major infrastructure can appear to be decisive for the envisagable future: effectively for all time. Infrastructure planning can thus open out the temporal horizon by proposing action in the near future that will have consequences beyond the lifetime of those involved in the planning. Infrastructure planning helps to highlight the potential for the future to flip from orderly to threatening. A closer look at the attempts of infrastructure planners to be 'transparent' (see Garsten and de Montoya 2008) further highlights the internal contradiction between planning and participation.

Åsa Boholm and her colleagues have written extensively about their research on the planning an implementation of a major railway improvement on the West Coast of Sweden (2000). Boholm herself describes the design of railway infrastructure as 'hypercomplex' (in press). During the 1990s and 2000's (and ongoing), the Swedish National Rail Administration, Banverket, undertook a project for the Swedish government, to upgrade the single-track railway line between Gothenburg and Lund along the south-western coast of Sweden. The project was administered through a series of parallel development projects; Banverket approached each municipality with a proposal for the stretch of rail through that municipality, including the main station. The municipalities then considered the proposals, discussed them and consulted on them. In each case, one or several protest groups appeared with some objection to the proposals, and in each case this led to a broader debate, in some cases protests, and in some cases legal action, public enquiries and even EU environmental court cases (see Abram and Strandberg 2005). The key issues for debate in each municipality were the safety of running high speed trains through narrow urban corridors or popular recreation areas, or whether lines should be moved out of town and stations re-sited. Different constellations emerged around each proposal, with one municipality supporting out-of-town station relocation with opposition from residents' groups, while another municipality supported keeping the station in town, with opposition form residents' groups there. These proposals raised questions 
about the legitimacy of decision-making processes, how the authorities should respond to protest groups, and how protest groups could make themselves heard. These, in turn, raised questions about how different kinds of knowledge were made instrumental during the debates about the plans.

Formally, Swedish municipalities have a monopoly over municipal planning, as one municipal planner explained: 'the whole legal apparatus is built on the principle that, quite simply, the local society decides over conflicts', but this definition does little to illuminate how 'local society' is constituted. Local politicians claim a privileged ability to understand local society holistically and thus to represent collective interests. One council chair, for instance, summarized this position in contrast to the fleeting interests of other citizens: 'Lots of people...young families, they look to child-care and schools, that's important, and only that's important. Later it's other things; it'll be care for the elderly that is the only thing one looks to. So it is up to us politicians to try to take account of the whole, for society, and for the consequences'. They described their own role as leaders, or as builders of society: 'to look forward, plan for the future, what's best from a social development perspective'. This role also demanded of their own time, and they contrasted this with what they saw as short-term horizons of private citizens: 'In complex issues, which will affect the future colossally, if you send the question out to people who haven't got stuck into them, who just think about it over a coffee break and then spontaneously choose something, well that's to build infrastructure in a way which I don't think is particularly good, and not one for an insightful politician'. Thus, as well as claiming authority over spatial oversight, and the ability to assess competing interests, the politicians claimed temporal authority as well.

Their concern with consequences was shared by members of protest groups, who rejected the image of themselves as ignorant and self-interested. On the contrary, they were at pains to point out that they were campaigning for the public good: 'to try to ensure that the national interest is preserved, and that the West Coast line is developed in an optimal way'. Members of the protest groups talked much more widely than others of the temporal context of current dilemmas. They referred to plans from the 1950s and before, and they saw the implications of the current plans potentially lasting into the foreseeable future. But they also described ruptures in this long span, when, for example, after generations of plans identifying transport development located near the motorway, 'suddenly, we were so surprised, that the municipality took a decision to develop the West Coast line on the current track, through our recreation area, coastal zone, through the small boat harbour, the town and through the hospital grounds'. Indignant surprise related to what appeared as the sudden unpredictable decisions of the municipality, which until then had followed known policies and procedures.

One way they attempted to secure the quality of the development was by bringing technical issues to the attention of Banverket. What distinguished these protesters from the authorities in our discussions was their marked concern with the past, in contrast to the officials' over-riding concern with the future. There were several examples of historical knowledge being brought into the planning process by organisations set up to make objections to the plans. One group contacted a professor of geology from Stockholm whose phd supervisor had had his summer house in the area. The geologist had done his dissertation research there, within a kilometre of the proposed tunnel site, and he was commissioned by the group to conduct a safety assessment of the site. He identified a number of critical crack zones and the group tried to bring these to the attention of Banverket. Many of them complained that Banverket had lost the detailed technical expertise it had once had, and they were shocked that the engineers and politicians did not seek to share their detailed 
historical knowledge of the geology and ecology of the different development routes. While they had sympathy for the heavy responsibilities taken by local politicians, they were critical to what they saw as their failure to live up to the ideal of a rational juridical political decision-making process. What they saw was the less respectable 'realpolitic', provoking righteous protest: '...if they [local politicians] don't decide in your favour, well you just have to put up with it, in a democracy. But when you feel that they won't listen, that they avoid the question, that they change the agenda or act on prior parameters to get the result they first wanted, I react against that'.

Municipal planners shared some of this scepticism about Banverket's knowledge. 'There's been nothing like it since the end of the 1800s in Skåne. So their knowledge about this kind of project had to be built up as they went along, quite simply. Not least the questions of risk and so forth' (Senior municipal planners/architects). The planners' concern was with knowledge to be produced in a forwards trajectory, as historical knowledge had disappeared, a viewpoint shared between the formal actors. Local politicians' remarks on this longer perspective had an entirely forward-looking direction: 'we are evaluating an infrastructure project, and obviously we need a hundred years' perspective, ...we have to take the responsibility to look forwards, to plan for the future, as best we can'. Yet even when the protesters were looking forward, they were also immediately concerned about losing the goods from past development: 'this is our municipality's most important decision for this century at least, and it affects future generations, [our town's] development and North West Skåne's [the region's] development... which has a superb communications infrastructure, which they're now frittering away'. A sense of scale is suggested that conjures a long history of slow development, where a sudden rupture imperils the qualities of the future. In this regard, the proposed plan operates as a temporal hinge from a secure past to loss in the present, and from a known future to an unknown future. One might argue that the position of the planners and managers evacuated the near past rather than the near future. Historical conditions leading up to the plan were consistently overlooked in planning, while forming the core of the rationalities presented by objectors. Objectors were concerned about changing the temporal direction from the steady progress from the known past into unevented future that they had anticipated, into an unknown and highly unstable future, while planners could be said to be concerned with the progression from present towards a planned future-vision.

The greatest concern for the Banverket managers, on the other hand, was the time taken to produce the plans for the railway works. A municipal committee chair spelt this out: 'these are projects that take and incredibly long time and demand an incredible amount of engagement from the municipality'. The project managers most clearly created a proportional relation between time for democracy and time for engineering progress, seeing time taken to make decisions as a delay for building. For managers working in an environment where problem-solving is highly valued, negotiations between state agencies and political debates at the local level appeared to be unnecessary bureaucratic formalism:

'we could get the same result considerably more promptly by bringing together the different departments, if we arranged one meeting and went through the matter, adjourned one or two weeks and arranged a new meeting so we could get to a common understanding on the matter' (Ibid, 9).

With some irony, one questioned whether the drawn-out process is a necessary evil in a democratic society:

So it takes eight years to investigate everything, and two years to build, today that's approximately the relative times. So you have to wonder, which part could be reduced? Or is it an end in itself, to take such a long time so people have time to get used to the change that is on the way? (District rail administration manager).

The managers were very much aware of the problems caused by a drawn-out state of doubt, including what is known as planning blight: 'people don't know whether to sell their house or move'. In other words, a democratic decision-making process requires an excess of time, and this has costs for those most directly 
involved. On the one hand, managers criticized self-interested objectors, but sympathized with those affected by planning blight. Their sympathy is not for those who complain when they see that development will affect them personally for the worse, but for those who suffer from a lack of decision which prevents them from pre-empting or counteracting the effects of development. This brings us back to the municipal planners that were critical of the apparently sudden complaints late in the process, by newcomers to the debate. In their commentaries, they began to explain, and de-legitimize, the participation of protest groups at late stages in the process, insisting, for example, that 'there's been complete political unanimity in getting the West Coast Line, everyone has agreed on it right through the process' (Senior municipal planners/architects). Municipal chairs also struggled with this, perceiving a silent antipathy that failed to make itself known at the right time, rather than objections that emerged later. Planners explained late-emerging protest as a sign of process failure:

Probably the most important experience is that early discussions need plenty of time. It's essential, to raise different viewpoints and alternatives. And in some of those earlier projects there was such a rush to get going, and I think that's really affected those projects. And there's a more general point, in terms of the role and significance of social planning: Democracy takes time (senior municipal planners/architects).

The municipal planners thus articulated a tension between time, political expediency and technical solutions. They were able to reason that problems lay in poor public understanding of complex issues, rather than public discovery of errors: 'I don't know, my general experience of this kind of big project is that people only start to concern themselves when it starts to affect their own back yard, quite simply' (Ibid, 20). This references the usual 'nimby' accusation with the inference that self-interest emerges at late stages of a process, a widespread complaint amongst planners, more generally, that the 'general public doesn't care', a complaint which stems from a particular interpretation of the patterns of public engagement in planning processes (Muller and Kohutek 2002, Neveu 2002) and continues despite counter-evidence (Abram 2001), and despite arguments that it is interest generally that grows as a project comes closer (Wolsink 2005). The problem with the public was further projected away from the (temporal aspects of) management of the decision-making process onto the lack of rationality amongst the public, as seen by the railway projectmanagers. For the municipal planners, the problem lay not with the overall project, but with the detail, and with the self-interest versus the national or general interest. Difficulties in the process and the emergence of protest at awkward times was not, for them, a question of errors or shortcomings in the detailed planning of the infrastructure, but a general question of interest resolution: '... this problem of the balance between general interest and the special interest. It's the basic issue in planning that we are always confronting. It's not unique to this situation' (Ibid, 25).

This chimes with the suggestions made by protest groups that their arguments were not listened to, but categorized as irrelevant or out of context. Even though the protest groups framed their objections in terms of general environmental questions, regional economic solutions, and so on, in other words, despite using the discourse of government and general interest, it appears that the detail of their arguments was never scrutinized. They were perceived, instead, as posing problems for time-efficiency of planning processes. There was no discussion of local protesters potentially alerting the authorities to technical or environmental problems which might cause significant delays or costs for the overall project further down the line.

This is a generalized problem with participative planning processes that are designed by planners to follow a progression through time which involves the initiation into both governmental technologies (how to be a participant) and into project aims (learning to share the plan's ambitions). An open process is one in which meetings are held in public and technical information is shared relatively openly. The contradiction can be explained relatively simply as an instance of the distinction between knowledge and information. According to Corsin-Jimenez (2011) for information to circulate freely, it must be outside particular social relations. Knowledge, on the 
other hand, is learned implicitly in the context of morally framed relations. When new participants appear at planning meetings sometimes years into the planning process, they may be in possession of information, but have not been inducted into the shared knowledge of the participants to previous planning procedures. Planners and managers are thus faced with the potential necessity to either revisit or rehearse the earlier stages of the planning process. An open public participative process thus presents a contradiction to the idea of progress through participation, since participative processes imply that participants learn from each other and from the experience of participation. The missing element is thus the learning that is gained from the participation over time. The contradiction is highlighted by the notion of a general public to whom participation must always be open, as noted above. Repeated calls by planners and managers for early participation indicates their reliance on a temporal progression through which participants can learn to share the planners' aims, and different views can be evaluated at the initial stages of any planning. Faced with new objections to early decisions, they found fault with the organization of participation or with the quality of motivation of the participants rather than with the limits to their expectations of their own potential learning from informal participants, or the limits to the compatibility between democratic participative politics and technical design.

\section{Rescaling futures, layering temporalities}

A series of relevant temporal frames emerge from this brief foray into an ethnographic field of planning ${ }^{\mathrm{vi}}$. These could be articulated as follows:

- different futures envisioned in the process of planning, scaled at different degrees of abstraction in both time and space, some of which are textualised in planning documents;

- changes that are happening outside the planning process, that the plans must pay attention to, either through mapping trends, noting events or changes at different scales (from demographic changes to international markets to local ecological effects)

- temporal cycles of preparing, making and agreeing planning documents and their policies;

- the time taken to pursue the process of creating each plan and review it at various points, depending on the scale of the future imagined within it;

- progress towards planning aims, assessed and evaluated at various points;

Each of these is also subject to temporal cycles on other scales, such as the reformulation of national policies, the electoral cycle, turnover of personnel in the municipal bureaucracy, and so forth. But it would be wrong to assume that each of these temporal frames was static in its own right. They also change, sometimes abruptly, sometimes more slowly. Planning frameworks are subject to national and international fads (see Abrahamson 1991), and policy cycles often vary. But also the methods for envisioning the future have varied, with new techniques appearing at various times. In my own ethnographic research on the creation of future-plans (10-20 district or regional plans) in England and Norway, I have been concerned with the governmental techniques that organize knowledge about the world into usable information, and the consequences of these both for people involved in planning and the people and places planned-for (see Abram 2003, 2011). In these cases, future scenarios were imagined based on recent trends. The future was thus extrapolated from experience, and policies were invented to adapt to these (Murdoch and Abram 2002). Such processes could be understood as self-fulfilling prophecies, and objectors to plans often found themselves excluded from the planning process by the kind of 'muting' effects that Edwin 
Ardener identified (Ardener 1975), including those described above. Since then, however, trendbased planning has been challenged by new techniques to create future plans and visions. British planners are increasingly adopting a technique called 'backcasting'. Whereas forecasting takes current trends, extrapolates them to a distance future and invents policies to adapt to that future, backcasting starts with a desired future and invents policies to achieve it (see Holmberg and Robèrt 2000). The difference may sound subtle, but the concept of time is altered. Whereas forecasting sees the future as the inevitable outcome of the present, backcasting casts the future as a malleable result of present and future decisions. It thus gathers potential and agency to the near-future, endowing it with the means to achieve desired outcomes, rather than merely succumbing to the trends set in the past.

Another very brief example will make this more explicit. Planning for housing in England has been subject to a regime of numbers that collects statistical information about household formation, dwelling construction, and a range of demographic and commercial factors, such as the demand for office and domestic space measured through 'vacancy rates' (which record the proportion of such facilities available). Based on trends identified by these numbers, predictions are made about the need for future development. There is a subtle slip in the process between the measurement of past demand to the prediction of future need, but challenging the numbers on this basis is futile as the numbers become immutable in the process of moving up and down planning hierarchies (Murdoch and Abram 2002). The effect is that areas that experience high rates of growth are allocated future development growth, and areas that are well protected continue to be protected. These predictions are then aligned with policies that reinforce the divisive effects. Trends thus procure a forward drive that is unrelated to situated experience. Whereas residents may feel that they need time to adjust to a period of rapid growth, or that they have had their 'fair share' of growth in areas of pressure, the trends ensure that rapid growth continues. Backcasting the future, on the other hand, might start with a vision of the kind of development that would be desirable where, and adopt strategies to direct growth to areas where it is seen as either appropriate or desirable. To some extent, the planning in the Norwegian example could be considered a version of backcasting. A deputy director in the municipality described a planning process she had observed in another district, where a public survey had invited residents to say what they wanted from a future-district. Suggestions which merely suggested spending money were filtered out, while others were mapped and discussed in political debate, becoming the basis for specific policies, thus working back from a desired future rather than extrapolating from the present.

Both methods of future-planning are fallible and subject to political manipulation, of course, and it could well be argued that as models they are rarely applied in any pure form, but the explicit adoption of new techniques indicates that it is possible to recast what the future is, and to reimagine the temporal frame of the passage from present to future envisaged in planning. They also imply that time can be imagined forward and backwards, as well as cyclically. Backcasting, as its name implies, works back through time, but planning processes can also be retrospective. Sarah Lund describes the how land invasions in peri-urban Peru start with the construction of dwellings and then work backwards towards the retrospective adoption of local planning regulations, perhaps over a lifetime (2011). In my experience of English and Norwegian plans, it is otherwise very rare that the past is considered to any great degree in forward-plans. A longer perspective on the historical development of a place, for example, is conspicuously absent from all the plans that I have read, and rather than evacuating the near future, strategic or forward plans such plans tend, instead, to 
evacuate the near past (or the distant past, for that matter). This willful ignorance of time past leads often to both distress and distrust among people who come into contact with plans. What is perhaps remarkable is how robust governmental planning remains despite the continued hollowing out of the welfare state. As an increasing range of services is organized through contracts with third party organisations, and criteria for services are organized centrally by state governments, political actors are left with budget responsibility rather than management accountability, and hence with a radically reduced political possibilities. It is possible that governments attempt to compensate for the evacuated near future by filling it with land-use plans, but it is equally possible that public servants are using plans to try to counteract the erosion of their roles. However we choose to speculate on the politics of planning, it is clear that governing the future is an ambition that recruits many and multilayered temporalities.

There appears, therefore, to be a lot going on in the neoliberalization of the state that precludes a singular judgement about the effects on temporality of the kind that are often favoured by anthropological publications. In anthropology, discussion of temporalities has been dominated by discussions of anthropology's relationships to time and other kinds of reckoning. Postill's stinging critique of the anthropologists of time (2002) is itself concerned with the spread of clock and calendar time, rather than an exploration of the variation and manipulation within this apparently global time schedule. Zonabend's (1994) offers recognition that different temporalities flow in parallel, where cycles of different length (diurnal, lifecycle) happen alongside historical and event time, which itself is not seen as unilinear, but uneven, flowing in fits and starts around the breakwaters of significant eras. In contrast, recent discussions of neoliberal time have been much more focused on expert technologies of prediction (e.g. Lakoff 2008, Zaloom 2009) but are similarly singularly focused on one kind of time at a time, although Zaloom does offer ethnography of how the technology is done, as well as how it projects over time. Somewhere between these core approaches, addressing changing regimes of everyday time, asking how anthropology deals with history, or how scientific technologies are used to cope with uncertainty, we need to make room to see the layering and folding of presents and futures that persist from modern into neo-liberalizing states. Expert technologies need to be seen in a broader frame, in the light of attempts to derail them, encounters with non-believers and contradictory temporalities. Planning technologies may seem to presume a particular temporal flow, yet in the practice of planning, the encounter with the non-initiated repeatedly throws up the same problems, preventing planning techniques from rolling smoothly on, and ensuring that the promises of planning remain elusive. Planning itself takes time, and during the time it takes, circumstances change, ambitions alter, and different participants arrive on the scene, and all the participants (ethnographer included) continue to learn about the planning process and what it entails.

\section{References}

Abram, S. (2011). Culture and Planning. Aldershot: Ashgate

Abram, S. (2007a) 'Participatory depoliticisation: the bleeding heart of neo-liberalism'. In Catherine Neveu (Ed.) Cultures et pratiques participatives: perspectives comparatives Paris: l'Harmattan: 113-133. 
Abram, S. (2007b) 'Loyalty and Politics: The discourses of liberalisation' in S Ardener and F Moore (Eds) Professional Identities: Policy and Practice in Business and Bureaucracy. Oxford: Berghahn: 87-107

Abram, S. 2003. Anthropologies in policies, anthropologies in places. In T. Hylland Eriksen (ed.) Globalisation: Studies in Anthropology Pluto Press. Pp 138-157.

Abram, S. \& R. Cowell 2004. Learning Policy-The Contextual Curtain and Conceptual Barriers. European Planning Studies 12, 209-228.

Abram, S. \& U. Strandberg (2005) Six controversies in search of an epistemology. Gothenburg: CEFOS Working Paper 4.

Abram, S. and G. Weszkalnys (2011) Introduction: Anthropologies of planning - Temporality, imagination, and ethnography. Focaal-Journal of Global and Historical Anthropology 61 (2011): $3-18$.

Abram, S. and G. Weszkalnys (Eds.) (in press) Elusive Promises: Planning in the Contemporary World. Oxford: Berghahn.

Abrahamson, E. (1991) Managerial Fads and Fashions: The Diffusion and Rejection of Innovations. Academy of Management Review 16: 586-612.

Adams, V., M. Murphy and A. E. Clarke (2009) Anticipation: Technoscience, life, affect, temporality. Subjectivity 28:246-265.

Anton, T. J. (1969) Politics and Planning in a Swedish Suburb. Journal of the American Institute of Planners 35(4) 253-263.

Ardener, E. (1975). Belief and the problem of women. In S. Ardener, (Ed.), Perceiving women. London: Malaby Press. Pp.1-17

Arnstein, S. R. (1969) A Ladder of Citizen Participation. Journal of the American Institute of Planners 35(4) 216-224.

Baxstrom, R. (2012) Living on the Horizon of the Everlasting Present: Power, planning and the emergence of baroque forms of life in urban Malaysia. In L. Chua, J. Cook, N. Long and L. Wilson (Eds) Southeast Asia Perspectives on Power. Abingdon: Routledge. 135-150

Boholm, Å. (2000) National objectives - local objections : Railroad modernization in sweden. Gothenburg: Center for Public Sector Research (CEFOS).

Boholm, Å. (in press) From Within a Community of Planners: Hypercomplexity in Railway Design Work. In S. Abram and G. Weszkalnys (Eds) Elusive Promises: Planning in the Contemporary World. Oxford: Berghahn.

Corsín Jiménez, A. (2011) Trust in Anthropology. Anthropological Theory. 11(2) 177-196.

Crapanzano, V. (2007) Co-futures. American Ethnologist 34(3): 422-425. 
Damer, S. and C. Hague (1971) Public Participation in Planning: A Review The Town Planning Review 42 (3): 217-232.

DCLG (Department for Communities and Local Government) (2012) National Planning Policy Framework. Crown Copyright.

Dolowitz, D and Marsh, D (1996) Who learns what from whom. Political Studies 14(2): 343-357.

Dolowitz, D and Marsh, D (1996) Learning from Abroad: The Role of Policy Transfer in

Contemporary Policy-Making. Governance: An International Journal of Policy and Administration, 13(1): 5-24.

Garsten, C. and M. L. de Montoya (2008) Transparency In A New Global Order:

Unveiling Organizational Visions. Cheltenham: Edward Elgar.

Guyer, Jane I. (2007a). Prophecy and the Near Future: Thoughts on macroeconomic, evangelical and punctuated time. American Ethnologist 34(3): 409-421.

Guyer, Jane I. (2007b) Further: A rejoinder. American Ethnologist 34(3):447-450.

Holmberg, J. and K-H. Robèrt, (2000). Backcasting from non-overlapping sustainability principles - a framework for strategic planning. International Journal of Sustainable Development and World Ecology 7:291-308.

KS (kommunenes interesse- og arbeidsgiverorganisasjon [Local Government Association]) (Undated) Inspirasjonshefte om kommunale planstrategier - et verktøy for ønsket samfunnsutvikling [Advice on municipal planning strategies - a tool for desired social development]. Oslo: KS.

Lakoff, A. (2008) The Generic Biothreat, or, How We Became Unprepared. Cultural Anthropology 23(3): 399-428.

Lund, Sarah (2011) Invaded city: Structuring urban landscapes on the margins of the possible in Peru. Focaal 61 : 33-45.

Miljøverndepartementet [Norwegian Ministry of Environment] Veileder: Kommunal planstrategi [Guidance on municipal planning strategies]. T-1494 Miljøverndepartementet. http://www.regjeringen.no/pages/17299458/T-1494.pdf

Mogulof, M. (1969) Coalition to Adversary: Citizen participation in three federal programs. Journal of the American Institute of Planners 35(4) 225-232.

Muller, B. and Kohutek, P. 2002. Engaging the new democracy: The power of participation in the post-communist czech republic. Focaal, pp. 67-82

Murdoch, J. \& S. Abram. (2002). Rationalities of planning : development versus environment in planning for housing. Aldershot: Ashgate.

Neveu, C. 2002. Nimbys as citizens: (re)defining the 'general interest'. Focaal, pp. 51-66

Peck, J. and A. Tickell (2002) Neoliberalizing space. Antipode 34(3): 380-404.

Postill, J. (2002) Clock and Calendar Time: A missing anthropological problem. Time \& Society. 11(2/3): 251-270. 
Pusey, M. (1998) Between Economic Dissolution and the Return of the Social: The Contest for Civil Society in Australia. In J. Alexander (ed.), Real Civil Societies. Dilemmas of Institutionalization. London: Sage Publications.

Rabinow, P. (1989) French Modern: Norms and forms of the social environment. Chicago: University of Chicago Press.

Rose, R (1993) Lesson Drawing in Public Policy Chatham, NJ: Chatham House

RTPI (Royal Town Planning Institute) (2007) Planning With Communities. RTPI.

Skeffington/Ministry of Housing and Local Government (1969) People and Planning: Report of the Skeffington committee on public participation in planning. HMSO.

Strandberg, U. (2004) 'Västkustbanan och medborgarna. Resultat från en enkätundersökning genomförd hösten 2002'. Arbetsrapport 29, 2003. Göteborg: CEFOS.

Vike, H. (in press) Utopian Time and Contemporary Time: Temporal Dimensions of Planning and Reform in the Norwegian Welfare State. In S. Abram and G. Weszkalnys (Eds) Elusive Promises: Planning in the Contemporary World. Oxford: Berghahn.

Wilk, R. (2007) It's About Time: A commentary on Guyer. American Ethnologist 34(3): 440-443.

Wittrock, B. 2000. Modernity: one, none, or many? European origins and modernity as a global condition. Daedalus 129(1): 31-60.

Wolsink, M. (2005) Wind power implementation: The nature of public attitudes: Equity and fairness instead of 'backyard motives'. Renewable and Sustainable Energy Reviews 11: 1188-1207

Zaloom, C. (2009) How to Read the Future: The yield curve, affect, and financial prediction. Public Culture 21(2): 245-268.

Zaloom, C (2007) Future Knowledge. American Ethnologist 34(3): 444-446.

Zonabend, F. (1984) The Enduring Memory: Time and history in a French Village. Manchester: Manchester University Press.

\footnotetext{
${ }^{\mathrm{i}}$ Guyer choses to focus on monetarism as a theory and professional practice, and not on neoliberalism as an ideology. One reason for this was to recognize that monetarism 'is precisely not just an ideology but also a massive created edifice of specific research and implementation measures in the financial world that has already shaped people's sensibilities and perceptions, if not to the point of a naturalistic acceptance of them as somehow generically human, then at least to the kind of lulled and muted self-referentiality that anthropology has always worked to challenge.' (2007b:448).

${ }^{\text {ii }}$ From Kommuneplan for Asker 2007-2020

iii ethnographic fieldwork was supported by the ESRC and the Department of Social Anthropology at the University of Oslo.

${ }^{\text {iv }}$ I am using pseudonyms in this article, even though the discussions were held in the public domain, as I will not have an opportunity to consult the participants before publication.

$v$ For a discussion of the production of a public by public sector agencies, and of the notion of educating the public, see Abram 2011.
} 
vi For the sake of clarity and brevity, I have mentioned relatively little in this discussion about the effects of investment cycles and developer shareholder demands on the actual physical building process that plans envisage, nor the immediate bureaucratic regulatory practices of development control, planning permission applications, building regulations or planning-decision enforcement. Each provides a further layer of dispute, uncertainty, and multi-party mediation. 